\title{
STUDY OF CORONARY ARTERY DISEASE IN WOMEN- THE INCIDENCE OF RISK FACTORS AND CLINICAL PROFILE
}

\author{
Thiagarajan Chakravarthi', Sappani Kasipandian², Pasupulati Venkatasamy Krishnan³
}

1 Junior Resident, Department of Medicine, KAP Viswanatham Government Medical College, Tiruchirapalli, Tamilnadu. ${ }^{2}$ Associate Professor, Department of Medicine, KAP Viswanatham Government Medical College, Tiruchirapalli, Tamilnadu. ${ }^{3}$ Associate Professor, Department of Medicine, KAP Viswanatham Government Medical College, Tiruchirapalli, Tamilnadu.

\section{ABSTRACT}

\section{BACKGROUND}

Coronary Artery Disease (CAD) is the leading cause of death among women and accounts for more number of deaths than from other non-communicable diseases. Both systolic and diastolic hypertension produce more CAD events. Lowering of BP decreases Myocardial Infarction (MI) and sudden death risk. CAD risk is slightly higher among women between 49 to 89 years of age and our study showed more CAD occurred in 41 (51.25\%) patients between 46-59 years of age. This study is conducted to find out the incidence of risk factors Diabetes Mellitus, Hypertension, Dyslipidaemia, Surgical/Natural Menopause and clinical profiles of CAD in women.

\section{MATERIALS AND METHODS}

A total of 80 female patients with the age of 38 to 80 years with clinical background of symptoms and ECG or Echo evidence of CAD admitted in M.G.M. Govt. Hospital, Tiruchirapalli.

\section{RESULTS}

Our study showed ST-segment Elevation Myocardial Infarction (STEMI), 33 (41.25\%) patients, is more common than Non-ST segment Elevation Myocardial Infarction (NSTEMI), 16 (20\%) patients, and also more STEMI in premenopausal (71.4\%) than postmenopausal (34.8\%). Arrhythmias are more common in women than men. Obesity, diabetes mellitus with poor glycaemic control, increased triglyceride, decreased HDL cholesterol play a significant role for the causation of CAD among newly detected patients and premenopausal than post-menopausal patients.

\section{CONCLUSION}

Obesity and other components of metabolic syndrome are the most important risk factors for CAD. Typical anginal symptoms of CAD are not present in old and diabetic patients, so delayed hospitalisation results in high mortality and morbidity due to fatal arrhythmias and evolved myocardial infarction leads to severe cardiac muscle damage and congestive cardiac failure (CCF). CAD mortality rate will be decreased if modifiable risk factors are identified early and treated properly.

\section{KEYWORDS}

Coronary Artery Disease, Pre-Menopause, Post-Menopause, Hypertension, Blood Sugar, Lipid Profile Body Mass Index.

HOW TO CITE THIS ARTICLE: Chakravarthi T, Kasipandian S, Krishnan PV. Study of coronary artery disease in women- The incidence of risk factors and clinical profile. J. Evolution Med. Dent. Sci. 2017;6(53):4042-4047, DOI: 10.14260/Jemds/2017/874

\section{BACKGROUND}

CAD remains the leading cause of death in women regardless of race or ethnicity. ${ }^{1}$ More women (52\%) than men $(42 \%)$ with Acute Coronary Syndrome (ACS) had sudden death before they reach the hospital. ${ }^{2}$ The world wide INTERHEART study has revealed that women develop Acute Myocardial Infarction (AMI) 10 years later than men, but mortality among women is greater than men. Obesity is defined as BMI $>29 \mathrm{~kg} / \mathrm{m}^{2}$. It increases the cardiovascular mortality in women and $35 \%$ of women are obese. ${ }^{3}$ Apple-shaped obesity has more risk than pear-shaped obesity (fat on the hips and buttocks). A greater waist circumference increases health risk regardless of BMI.

Financial or Other, Competing Interest: None.

Submission 01-02-2017, Peer Review 21-06-2017,

Acceptance 27-06-2017, Published 03-07-2017.

Corresponding Author:

Dr. Sappani Kasipandian,

Devi Illam, No. 3/423/5, Meenakshi Amman Street,

Opp. Pandi Kovil, Pandian Nagar, Madurai-625020.

E-mail: sankarkasipandian@yahoo.com

DOI: $10.14260 /$ jemds $/ 2017 / 874$

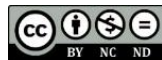

Enlarged waist circumference $(>88 \mathrm{~cm})$ along with elevated triglycerides (TGL) carry more CAD risk for postmenopausal women. $47 \%$ of women more than 20 years of age have a serum total cholesterol (TC) level $>200 \mathrm{mg} / \mathrm{dL}$ and $31.7 \%$ have Low Density Lipoprotein (LDL) cholesterol > $130 \mathrm{mg} / \mathrm{dL}$ according to AHA study. ${ }^{4}$ In post-menopausal period, TGL, TC, LDL are increased and High-Density Lipoprotein Cholesterol (HDL Cholesterol) declined gradually and leads to increased CAD risk.

In women oestrogen produces vasodilatation and it activates endothelial nitric oxide synthase which inhibits intimal hyperplasia, smooth muscle migration and promotes antioxidant effects. ${ }^{5}$ Oestrogen may be chronically protective against the development of atherosclerosis in women.

Apolipoprotein gene expression in response to oestrogen results in LDL reduction and HDL elevation thereby decreasing CAD risk. Women with early menopause after gynaecologic surgery are facing more CAD risks because of low hormone exposure. Hormone Replacement Therapy (HRT) with oestrogen alone is contraindicated because of endometrial cancer in women with uterus. Adding progesterone to oestrogen replacement therapy produces HDL rise. The importance of CAD and its prevention in women is receiving increased physician attention.6,7 Healthy 
lifestyle changes like half an hour exercise per day for 5 days in a week, adequate amount of fresh fruits and vegetables intake, diet rich in Poly Unsaturated Fatty Acids (PUFA), Mono Unsaturated Fatty Acids (FUFA), Omega-3 Fatty Acids, restriction of salt and diet with saturated fatty acids protect women from CAD.

\section{CAD Risk in Asian Women}

Among Asians, $50 \%$ of the all MI occur under the age of 50 years and $25 \%$ under the age 40 years. Excess burden of premature CAD in Asia is due to genetic susceptibility which is mediated by elevated level of Lipoprotein- (a) and smaller calibre of the coronary arteries.

The CAD mortality among Indians is greater in women than men, and among Asian women between 45-64 years of age is two times higher than the white women. Three-vessel disease on angiography is seen in one third (1/3) of premenopausal women. In Singapore, CAD mortality among Asian Indian women with 30-39 years of age is 8 times higher than Chinese women of same age.

From data in NHANES III (National Health and Nutrition Examination Survey) 90\% CAD events occur among those with at least one of the following risk factors e.g. Smoking, High BP, Low HDL level, and Glucose intolerance. When more than one risk factor is present, CAD risks are increased.

\section{CAD Statistics in India}

$12 \%$ CAD cases occur in urban areas, which is 4 times more than that of USA, 6 times more than that of Europe and 20 times more than that of Japan. ${ }^{6}$ Compared to males, CAD occurs 10 years later in females, 53 vs. 63 years of age, but mortality was higher in females than males $3 \%$ vs. $2 \%$. Low HDL is an important risk factor even if total cholesterol and triglyceride levels are normal. It is a stronger predictor of CAD in women than men. The optimum level of HDL among Indian females is $>45 \mathrm{mg} / \mathrm{dL}$. The NCEP ATP III has classified $\mathrm{HDL}<40 \mathrm{mg} / \mathrm{dL}$ as low and $>60 \mathrm{mg} / \mathrm{dL}$ as high. In India, $32 \%$ of urban and $18 \%$ of rural women have HDL levels $<40$ $\mathrm{mg} / \mathrm{dL}$. In the "Coronary Artery Disease in Indians" (CADI) study, $70 \%$ of Indian women had HDL levels $<50 \mathrm{mg} / \mathrm{dL}$. If the HDL level is $<35 \mathrm{mg} / \mathrm{dL}$, it confers an 8-fold higher risk for CAD than an HDL level of $>75 \mathrm{mg} / \mathrm{dL}$ in women. ${ }^{8}$ i.e. increased HDL level associated with decreased CAD risk.

\section{Aims and Objectives}

1. To find out the incidence of risk factors of CAD in women in and around Tiruchirapalli area.

2. To study the clinical profiles of CAD in women in \& around Tiruchirapalli area.

\section{MATERIALS AND METHODS}

\section{Study Setting}

Mahatma Gandhi Memorial Govt. Hospital attached to K.A.P. Viswanatham Govt. Medical College, Tiruchirapalli, Tamilnadu in collaboration with the Department of Cardiology.

\section{Study Period \& Duration}

September 2015 to February 2016, Six Months.

\section{Sample Size}

80 women patients.

\section{Study Design}

A retrospective observational Unicentric study.

\section{Ethical Committee Approval}

Obtained from the Institutional Ethical committee.

\section{Consent}

Individual written and informed consent obtained.

\section{Inclusion Criteria}

1. Patients with age of 38-89 years who were admitted with symptoms suggestive of CAD like, Chest pain, other Anginal equivalents like Dyspnoea, Giddiness, Nausea, Vomiting, Sweating, Palpitation, Epigastric discomfort and Tiredness.

2. Patients' ECG with Evidence of STEMI, NSTEMI and Pathological Q waves in Chest and Limb leads.

3. ECG with loss of $R$ wave in chest leads with significant $T$ inversion in more than 2-3 leads.

4. ECHO - RWMA status and features of poor LV functions. $(\mathrm{EF} \%)$.

\section{Exclusion Criteria}

1. Patients with Valvular Heart Disease \& Cardiomyopathy.

2. Symptomatic patients with Normal Serial ECGs and Normal Echo study.

3. Severe Anaemic patients with $\mathrm{Hb}<6 \mathrm{~g} \%$, Severe COPD patients.

4. Patients with previous history of abnormal Thyroid function test.

All the particulars were inquired by a questionnaire containing their history, personal history and family history.

\section{Methods of Collection of Data BP Recoding \\ BP was recorded in sitting, supine position with sphygmomanometer.}

\section{Calculation of BMI}

$\mathrm{BMI}=\mathrm{Wt}$. in $\mathrm{kg} / \mathrm{Ht}$ in $\mathrm{m}^{2}$

Height was measured with a tape to the nearest one centimetre. Patients were instructed to stand upright without shoes and chappals with their back against the wall, foot together and eyes directed forward.

Patient's weight was measured with weighing machine using spring balance that was kept on firm horizontal surface. Weight was recorded to the nearest $0.5 \mathrm{Kg}$.

The 12-lead ECG was the important tool for diagnosis of STEMI, NSTEMI, IHD/UA and Arrhythmias. Daily clinical examinations, ECG, ECHO findings documented and repeated as and when necessary.

\section{Blood Sample Collection}

Nearly $5 \mathrm{~mL}$ venous blood was collected for estimation of Random Blood Sugar (RBS), Urea, Creatinine, $\mathrm{HbA}_{1 \mathrm{c}}, \mathrm{Hb} \%$. Another $5 \mathrm{~mL}$ of venous blood was collected for Fasting Blood Sugar (FBS), Lipid profile after 8 hours fasting state and Postprandial Blood Sugar (PPBS) after two hours of breakfast were analysed with an Autoanalyser and the results were statistically analysed.

\section{Statistical Analysis of Data}

The information collected regarding all the cases were tabulated in a Master chart. Data was analysed with help of Statistical Software tool epidemiological information package 
(EPI 2002) and Sigma Stat 3.5 version. Using this Software, Ranges, Frequencies, Percentages, Means, Standard Deviations, and $p$ values were calculated through student ' $t$ ' test, and Chi square test. $P$ value $<0.05$ taken as significant.

(Due to limitation of tables and graphs, we put either table or graph for different variables. No relationship between table and graph on the same variable.)

\begin{tabular}{|c|c|c|c|c|}
\hline $\begin{array}{l}\text { Clinical \& Other } \\
\text { Parameters }\end{array}$ & Min & Max & Mean & S.D. \\
\hline Age - years & 38 & 80 & 55.29 & 10.994 \\
\hline Weight - kg & 46 & 80 & 63.28 & 7.144 \\
\hline Height- cm & 149 & 180 & 162.97 & 7.567 \\
\hline $\begin{array}{c}\mathrm{BMI}=\mathrm{Wt} \text { in } \mathrm{kg} / \mathrm{Ht} \text { in } \\
\mathrm{m}^{2}\end{array}$ & 17.36 & 35.56 & 23.9367 & 3.33910 \\
\hline TC- mg & 115 & 261 & 186.59 & 24.474 \\
\hline TGL - mg & 106 & 310 & 179.93 & 40.873 \\
\hline HDL- mg & 30 & 44 & 38.45 & 2.490 \\
\hline LDL- mg & 28 & 190 & 112.54 & 24.720 \\
\hline VLDL- mg & 21 & 62 & 35.99 & 8.175 \\
\hline Blood urea- mg & 14 & 42 & 25.95 & 6.601 \\
\hline Sr. Creatinine - mg & .60 & 1.60 & 0.9875 & 0.25364 \\
\hline $\mathrm{Hb}-\mathrm{g} \%$ & 6.00 & 11.50 & 9.3363 & 1.15969 \\
\hline $\mathrm{HbA}_{1 \mathrm{c}^{-}} \%$ & 4.6 & 9.5 & 7.5 & 1.5 \\
\hline Ejection Fraction - \% & 42 & 70 & 59.77 & 7.741 \\
\hline
\end{tabular}

\section{RESULTS}

This study was conducted in 80 women patients to find out the incidence of risk factors and clinical features of CAD. Of this $14(17.5 \%)$ patients were in Pre-menopausal group and $66(82.5 \%)$ patients were Post-menopausal group.

\begin{tabular}{|c|c|c|c|c|}
\hline $\begin{array}{l}\text { Age in } \\
\text { Years }\end{array}$ & $\begin{array}{c}\text { Pre Meno } \\
(n=14) \\
(17.5 \%)\end{array}$ & $\begin{array}{c}\text { Post Meno } \\
(\mathrm{n}=66) \\
(82.5 \%)\end{array}$ & $\begin{array}{c}\text { Total } \\
(n=80)\end{array}$ & $\begin{array}{l}\text { Statistical } \\
\text { Inference }\end{array}$ \\
\hline$<45$ & 14 & 0 & 14 & \multirow{3}{*}{$\begin{array}{c}\mathrm{X}^{2}=80.000 \\
\mathrm{Df}=2 \\
\mathrm{P} \text { value } \\
0.000<0.05 \\
\text { Significant }\end{array}$} \\
\hline 46 to 59 & 0 & $41(51.25 \%)$ & 41 & \\
\hline$>60$ & 0 & $25(31.25 \%)$ & 25 & \\
\hline \multicolumn{5}{|c|}{ Table 2. Age (Chi-square Test) } \\
\hline
\end{tabular}

\section{Age Distribution}

The mean age for Premenopausal group was 40 years, and the young MI that occurred in our study was 38 years. More CAD occurred in 41(51.25\%) patients between 46 to 59 years of age. (Chi square test used)

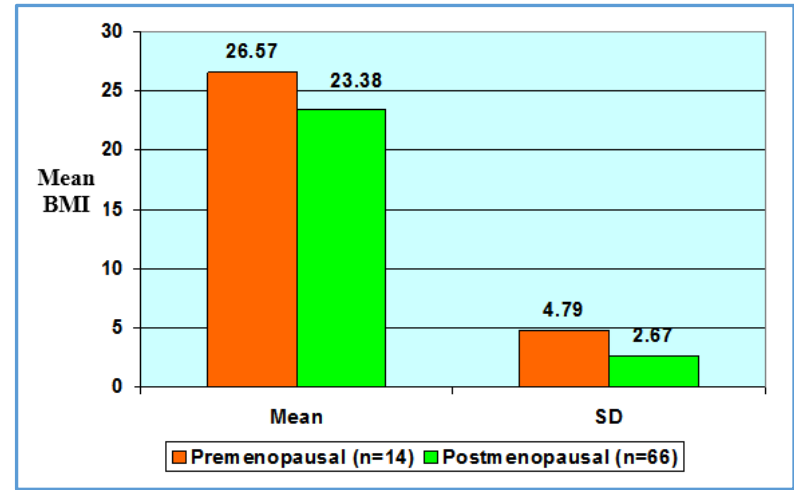

Graph 1. Comparison of Mean BMI. Premenopausal Women Vs. Post-menopausal Women

\section{Distribution of BMI}

In our study, the mean BMI among Pre-menopausal patients was 26.57, S.D. 4.79 which was higher than Post-menopausal patients (23.378 S.D. 2.671). We compared BMI between Pre and Post-menopausal age groups; the $\mathrm{p}$ value was significant (p 0.001). Obesity played a significant role for the causation of CAD among women. (Student ' $\mathrm{t}$ ' test used).

\section{Distribution of TGL}

We observed that mean TGL levels were significantly elevated in Pre-menopausal patients (mean TGL 191.86 mg/dL, S.D. 41.733) than Post-menopausal patients (mean TGL $177.39 \mathrm{mg} / \mathrm{dL}$ with S.D. of 40.76). The p value $<0.001$, significant (Student ' $\mathrm{t}$ ' test used).

\section{Distribution of TC}

On statistical analysis, we found that there was no significant alteration in mean TC between Pre and Post-menopausal patients $(184.57 \mathrm{mg} / \mathrm{dL}$, SD 22.3 vs. $187.02 \mathrm{mg} / \mathrm{dL}$, SD 25.049). The $p$ value was 0.645 , Not significant (Student ' $t$ ' test used).

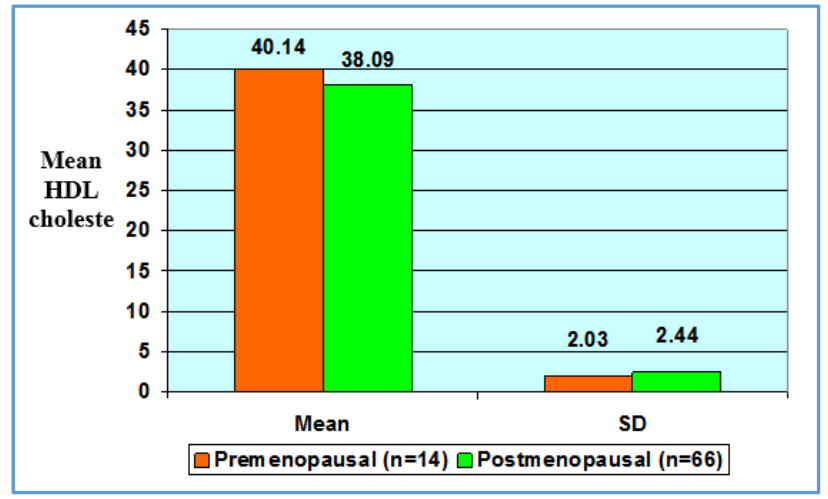

Graph 2. Comparison of Mean HDL Cholesterol. Premenopausal Women vs. Post-menopausal Women

\section{HDL Cholesterol}

In our study, the mean HDL cholesterol among Premenopausal patients $(40.14 \mathrm{mg} / \mathrm{dL}$, S.D. 2.033) was more than Post-menopausal patients $(38.09 \mathrm{mg} / \mathrm{dL}, \mathrm{SD} 2.441)$ and it was very significant on statistical analysis with a p value < 0.004. (Student ' $t$ ' test used).

\section{LDL Cholesterol}

In our study, there was not statistically significant difference in LDL Cholesterol level between Pre-menopausal vs. Postmenopausal patients $(106.06 \mathrm{mg} / \mathrm{dL}$, S.D. 18.607 vs. 113.91 $\mathrm{mg} / \mathrm{dL}$, S.D. 25.739). The p value was 0.283 , not significant. (Student ' $\mathrm{t}$ ' test used).

\section{VLDL Cholesterol}

We observed that there was no significant rise in serum VLDL cholesterol level between Pre and Post-menopausal patients ( $p$ value $0.23,70.05$ ). The mean value of VLDL cholesterol in pre-menopausal patients (38.37 mg/dL; S.D. 8.147) was more than the post-menopausal patients (35.48 mg/dL; S.D. 8.152). The $\mathrm{p}$ value was 0.232 , not significant (Student ' $\mathrm{t}$ ' test used). 


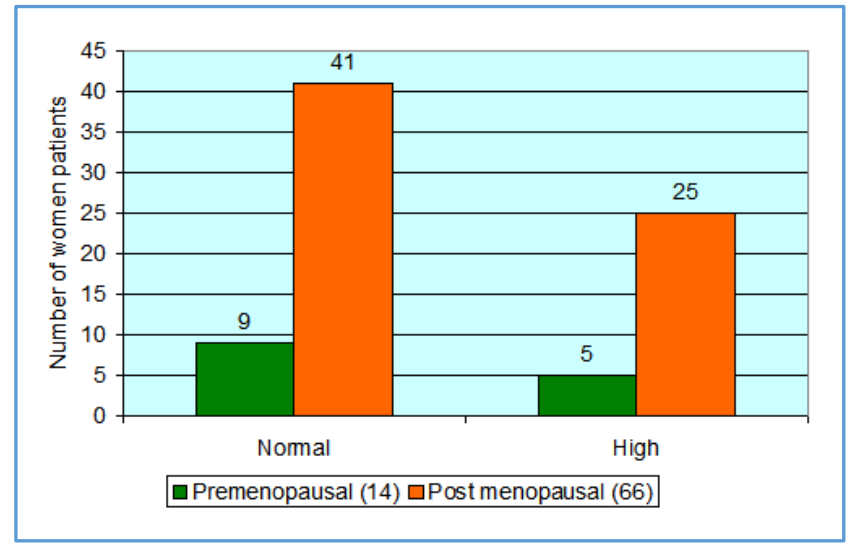

Graph 4. Comparison of BP in Pre and Post-menopausal Women

BP

There was no significant statistical difference in BP between Pre and post-menopausal patients. We observed that 30 (37.5 $\%)$ patients having high BP and 50 (62.5\%) patients had normal BP. The $\mathrm{p}$ value was 0.090 , not significant (Student ' $\mathrm{t}$ ' test used).

\begin{tabular}{|c|c|c|c|c|c|}
\hline $\begin{array}{c}\text { Types of } \\
\text { Patient }\end{array}$ & Mean & S.D. & t & Df & $\begin{array}{c}\text { Statistical } \\
\text { inference }\end{array}$ \\
\hline & FBS (mg) & & & & \\
\hline $\begin{array}{c}\text { Pre Meno } \\
(\mathrm{n}=14)\end{array}$ & 142.93 & 27.647 & 5.795 & 78 & $\begin{array}{c}0.007<0.05 \\
(\mathrm{p} \text { value) }\end{array}$ \\
\hline $\begin{array}{c}\text { Post Meno } \\
(\mathrm{n}=66)\end{array}$ & 99.53 & 24.990 & & & Significant \\
\hline & PPBS (mg) & & & & \\
\hline $\begin{array}{c}\text { Pre Meno } \\
(\mathrm{n}=14)\end{array}$ & 257.36 & 66.890 & 5.345 & 78 & $\begin{array}{c}0.001<0.05 \\
(\mathrm{p} \text { value) }\end{array}$ \\
\hline $\begin{array}{c}\text { Post Meno } \\
(\mathrm{n}=66)\end{array}$ & 159.85 & 60.980 & & & Significant \\
\hline $\begin{array}{c}\text { Table 3. Comparison of Fasting Blood Sugar and } \\
\text { Postprandial Blood Sugar with Pre and Post-menopausal } \\
\text { Women }\end{array}$ \\
\begin{tabular}{c}
$\mid 7$ \\
\hline
\end{tabular}
\end{tabular}

\section{FBS and PPBS}

In our study, the mean FBS value and SD in Premenopausal patients was $142.93 \mathrm{mg} / \mathrm{dL}$, S.D. 27.647 and in postmenopausal was $99.53 \mathrm{mg} / \mathrm{dL}$, S.D. 24.990 which was statistically significant with $\mathrm{p}$ value 0.007 (Student ' $\mathrm{t}$ ' test used).

PPBS value also got significant difference between Pre and Post-menopausal patients. $(257.36 \mathrm{mg} / \mathrm{dL}$; S.D. 66.89 vs. $159.82 \mathrm{mg} / \mathrm{dL}$, S.D. 60.98). The $\mathrm{p}$ value was $<0.001$, significant (Student ' $\mathrm{t}$ ' test used).

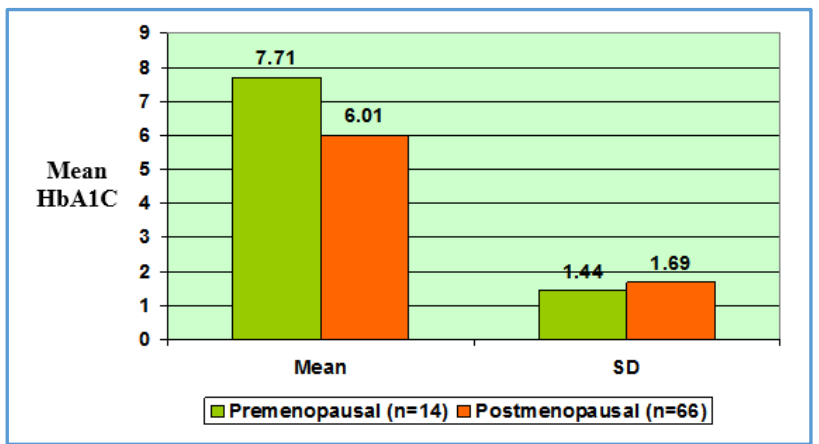

Graph 5. Comparison of Mean $\mathrm{HbA}_{1 \mathrm{C}}$ - Pre and Postmenopausal Women
$\mathrm{HbA}_{1 \mathrm{C}}$

We observed that $\mathrm{HbA}_{1 \mathrm{c}}$ was significantly elevated in Premenopausal patients $(7.71 \%, \quad$ S.D. 1.442) than Postmenopausal patients (6.01 \%, S.D. 1.69) and found very significant on statistical analysis with a $\mathrm{p}$ value of $<0.001$, significant. (Student ' $t$ ' test used).

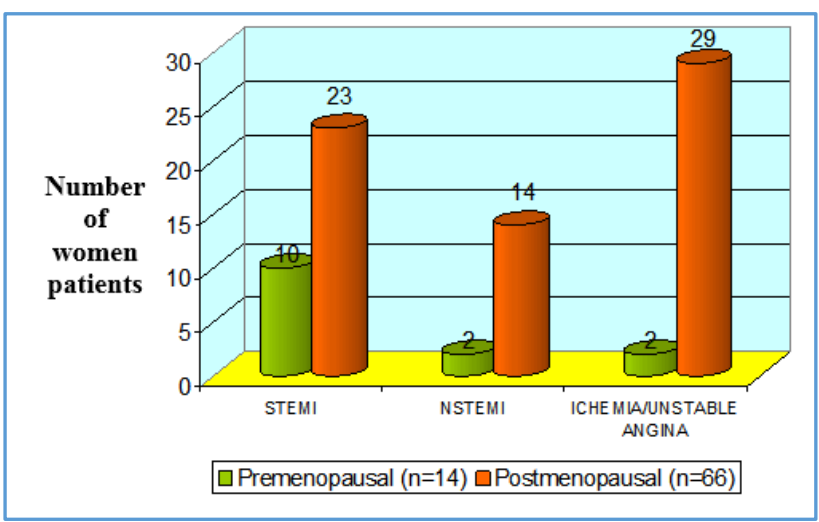

Graph 6. Comparison of ECG - Pre and Post-menopausal Women

ECG

In our study of the 80 patients, STEMI was observed in 33 $(41.2 \%)$ patients, NSTEMI in $16(20 \%)$ patients and Unstable angina/ ischaemia in 31 (38.8\%) patients.

STEMI was observed in $10(71.4 \%)$ Premenopausal and 23 (28.6\%) Post-menopausal patients. NSTEMI was observed in $2(12.5 \%)$ Premenopausal and 14 (87.5\%) Postmenopausal patients. Ischaemia/Unstable angina is observed in 2 (6.5\%) Premenopausal and 29 (93.5\%) in Postmenopausal patients.

In ECG, Q wave or evolved stage of MI was present in most of the old and diabetic female patients, most of them were silent MI.

\begin{tabular}{|c|c|c|c|c|c|}
\hline $\begin{array}{c}\text { RWMA } \\
\text { Particulars }\end{array}$ & $\begin{array}{c}\text { Pre } \\
\text { Meno } \\
(n=14)\end{array}$ & $\begin{array}{c}\text { Post } \\
\text { Meno } \\
(n=66) \\
\end{array}$ & $\begin{array}{c}\text { Total } \\
(n=80)\end{array}$ & $\%$ & $\begin{array}{l}\text { Statistical } \\
\text { inference }\end{array}$ \\
\hline $\begin{array}{l}\text { RWMA } \\
\text { Absent }\end{array}$ & 6 & 44 & 50 & 62.5 & $\begin{array}{c}\mathrm{X}^{2}=2.794 \\
\mathrm{Df}=1\end{array}$ \\
\hline $\begin{array}{l}\text { RWMA } \\
\text { Present }\end{array}$ & 8 & 22 & 30 & 37.5 & $\begin{array}{c}0.095>0.05 \\
\text { Not } \\
\text { Significant }\end{array}$ \\
\hline
\end{tabular}

Table 4. Comparison of Echocardiograph RWMA. Pre and Post-menopausal Patients

Chi square test used.

\section{Echocardiography}

a) RWMA (Regional wall motion abnormalities) were present in $30(37.5 \%)$ patients and absent in $50(62.5 \%)$ patients. RWMA present more in 8 (57\%) Premenopausal patients than 22 (33\%) in Post-menopausal patients but less severe RWMA in Pre-menopausal Patients than Post-menopausal patients. In patients who were hospitalised at the earliest in Hyperacute stage the treatment response was very good, so myocardial salvage was also good. 


\begin{tabular}{|c|c|c|c|c|c|}
\hline EF \% & $\begin{array}{c}\text { Pre } \\
\text { Meno } \\
(n=14)\end{array}$ & $\begin{array}{c}\text { Post } \\
\text { Meno } \\
(n=66)\end{array}$ & $\begin{array}{c}\text { Total } \\
(n=80)\end{array}$ & $\%$ & $\begin{array}{l}\text { Statistical } \\
\text { inference }\end{array}$ \\
\hline$<50$ & 0 & 12 & 12 & 15 & $\mathrm{X}^{2}=4.304 \mathrm{Df}=2$ \\
\hline 51 to 60 & 4 & 24 & 28 & 35 & $0.116>0.05$ \\
\hline$>60$ & 10 & 30 & 40 & 50 & Not Significant \\
\hline \multicolumn{6}{|c|}{$\begin{array}{c}\text { Table 5. Comparison of ECHO - Ejection Fraction EF\% Pre } \\
\text { and Post-menopausal Patients }\end{array}$} \\
\hline
\end{tabular}

Chi square test used.

b) EF \%-We observed statistically significant difference in EF between Pre and Postmenopausal patients (p $0.024<$ 0.05). The average EF\% among Premenopausal women was $64 \%$ S.D 5.491, and among Postmenopausal patients was 58.8\%, S.D 7.9. All Pre-menopausal patients (14) were found to have $50 \% \mathrm{EF}$ whereas 12 (18.18\%) Postmenopausal patients were found to have $<50 \%$ of $\mathrm{EF}, 10$ (71.45) Pre-menopausal patients have $60 \% \mathrm{EF}$ and 30 (45.45\%) Post-menopausal patients had $>60 \%$ EF. EF\% was good in Pre-menopausal patients than Postmenopausal patients.

\section{DISCUSSION}

CAD is the leading cause of death and a major cause of morbidity amongst women. Life expectancy has increased in India by 20 years to 61 years since 1960, so the incidence of CAD is increased. The post menopause increase in the risk of CAD is related to higher incidence of High BP, Diabetes mellitus, Dyslipidaemia and Obesity. Menopause is one of the important non-modifiable risk factor for CAD in females.

In our study of the 80 patients, $82.5 \%$ of were Postmenopausal and $17.5 \%$ were Pre-menopausal compared to Dwivedi et al study where Postmenopausal vs. Premenopausal females were $86.5 \%$ vs. $13.5 \%$ in 200 patients and $71.1 \%$ vs. $28.9 \%$ in 958 patients in a study done by Ricardo de Marchi et al.

In our study, CAD occurred between 46-59 years of age vs. 49-89 years of age in Rigotti et al study ${ }^{9}$ and $56-65$ years of age in Dwivedi et al study.

Obesity and other components of metabolic syndrome were noted as an important risk factor for CAD. In our study, $36.25 \%$ of women are obese which was closer to Ogden et al study $^{3}$ where $35 \%$ women were obese. In our study, the mean FBS $143 \mathrm{mg} / \mathrm{dL}$, PPBS $257 \mathrm{mg} / \mathrm{dL}$, and $\mathrm{HbA}_{1 \mathrm{c}} 7.7 \%$ were increased in Pre-menopausal patients than the Postmenopausal patients. FBS $100 \mathrm{mg} / \mathrm{dL}$, PPBS $166 \mathrm{mg} / \mathrm{dL}$, $\mathrm{HbA}_{1 \mathrm{C}} 6.0 \%$ and poor glycaemic control were noted in the newly diagnosed diabetic patients. The anginal symptoms of CAD was lacking in diabetic and old female patients, so they were presented with evolved stage of MI, CCF. Fatal Arrhythmias and sudden deaths are common due to delayed hospitalisation in these female patients.

In our study, mean TGL level and HDL Cholesterol level were increased in Pre-menopausal patients than Postmenopausal patients, but HDL was $<50 \mathrm{mg} / \mathrm{dL}$ and it was very significant. ( $p$ value $<0.001$ significant) which was similar to CADI study. ${ }^{8}$ No statistically significant difference of LDL, VLDL, BP level in Pre and Post-menopausal patients.

With the help of 12-lead ECG we diagnosed STEMI in 33 $(41.25 \%)$ patients, NSTEMI in $16(20 \%)$ patients and
Ischaemia/unstable angina in $31(38.75 \%)$ patients. STEMI is more common i.e. 10 out of 14 (71.4\%) in Premenopausal patients than Postmenopausal, 23 out of 66 (34.8\%).

Whereas more numbers of NSTEMI, Ischaemia/unstable angina were found in 43 (65\%) Post-menopausal patients than 4 (28.6\%) Pre-menopausal patients. Patients with severe typical symptoms of CAD with STEMI came very earlier to the hospital than the NSTEMI patients with mild or atypical symptoms of CAD. Also more care was given to the younger patients than the older patients by the family members.

Our suggestions for primary and secondary prevention of CAD are early identification by screening for risk factors and aggressive correction of risk factors of CAD by suitable relevant drugs and life style modification.

\section{CONCLUSION}

Obesity and other components of metabolic syndrome are the most important risk factors for CAD. Typical anginal symptoms of CAD are not present in old and diabetic patients, so delayed hospitalisation results in high mortality and morbidity due to fatal arrhythmias and evolved myocardial infarction leads to severe cardiac muscle damage and Congestive Cardiac Failure (CCF). CAD mortality rate will be decreased if modifiable risk factors are identified early and treated properly.

\section{Limitations of the Study}

1. More number of patients to be studied.

2. Tread Mill Test (TMT), Transoesophageal Echo and coronary angiography were not done.

3. Other finer sensitive tests like estimation of Apo A2, Apo B, Lip Protein (a) Highly sensitive C Reactive Protein, Serum Uric Acid, Urine Microalbuminuria and Plasminogen activator inhibitor (PAI), protein $\mathrm{S} \& \mathrm{C}$, Homocysteine, antiphospholipid antibody are not done.

4. Familial/Congenital dyslipidaemia needs further probe.

\section{REFERENCES}

[1] Lloyd-Jones D, Adams R, Carnethon M, et al. Heart disease and stoke statistics - 2009 update: a report from the American Heart Association Statistics Committee and Stroke Statistics Subcommittee. Circulation 2009;119(3):e21-181.

[2] Thom T, Haasse N, Rosamond W, et al. Heart disease and stroke statistics--2006 update: a report from the American Heart Association Statistics. Committee and Stroke Statistics Subcommittee. Circulation 2006;113(6):e85-151.

[3] Ogden CL, Carrdl MD, McDowell MA, et al. Obesity among adults in the United States: no statistically significant change since 2003-2004. NCHS Data Brief 2007;1:1-8.

[4] Shaw LJ, Bugiardini R, Merz CN. Women and Ischemic heart disease: evolving knowledge. J Am Coll Cardiol 2009;54(17):1561-75.

[5] Figueredo VM. The time has come for physicians to take notice: the impact of psychosocial stressors on the heart. AM J Med 2009;122(8):704-12. 
[6] Mosca I, Banka CI, Benjamin EJ, et al. Evidence based guidelines for cardiovascular disease prevention in women: 2007 update. Circulation 2007;115(11):1481-501.

[7] Mosca L, Linfante A, Benjamin E, et al. National study of physician awareness and adherence and cardiovascular disease prevention guidelines. Circulation 2005;111(4):499-510.
[8] Reddy KS, Prabhakaran D, Shah P. Estimation of cholesterol alone may fail to identify majority of high risk subjects for coronary heart disease. Indian Heart J 1997;49:597.

[9] Rigotti NA, Pipe AL, Benowirz NL, et al. Efficacy and safety of varenicline for smoking cessation in patients with cardiovascular disease: a randomized trial. Circulation 2010;121(2):221-9. 